\title{
Development of the Organizational Agility Maturity Model
}

\author{
Roy Wendler \\ TU Dresden \\ Faculty of Business Management and Economics \\ Chair of Information Systems, esp. IS in Manufacturing and Commerce \\ Helmholtzstr. 10, 01069 Dresden, Germany \\ Email: roy.wendler@tu-dresden.de
}

\begin{abstract}
The importance of organizational agility in a competitive environment is nowadays widely recognized and accepted. However, despite this awareness, the availability of tools and methods that support an organization in assessing and improving their organizational agility is scarce. Therefore, this study introduces the Organizational Agility Maturity Model in order to provide an easy-to-use yet powerful assessment tool for organizations in the software and IT service industry. Based on a design science research approach with a comprehensive literature review and an empirical investigation utilizing factor analysis, both scientific rigor as well as practical relevance is ensured. The applicability is further demonstrated by a cluster analysis identifying patterns of organizational agility that fit to the maturity model. The Organizational Agility Maturity Model further contributes to the field by providing a theoretically and empirically grounded structure of organizational agility supporting the efforts of developing a common understanding of the concept.
\end{abstract}

\section{INTRODUCTION}

$\mathbf{O}$ RGANIZATIONAL agility is an important and relevant concept for more and more organizations in today's competitive and fast-changing environment. Especially in the software and IT service industry, organizations are faced with an environment of rapid technological changes, which are accompanied by just as much change in customers' expectations and requirements [1], [2]. In addition, the fact that software and IT have become essential components of many other products - consumer electronics, automotive products, etc. - has increased the competitive pressure further [3].

However, despite an increasing awareness that organizational agility is a key concept in coping with this competitive pressure, the term "agility" is nowadays often inflated by many organizations without reasonable seriousness. Agility is nothing that can simply be put into practice. The management of an organization has to understand that the organization itself cannot be agile, but its employees can be. However, people are not independent from their environment, and they have to share appropriate skills in order to work under agile conditions and with suitable technologies [4], [5]. Hence, the path to an agile organization is a development process affecting all parts of an organization from workforce through organizational structures and processes to technologies used and the overall organizational culture [6], [7]. This process shows that managing the transition to an agile organization is a complex and strategic task. To fulfill this task, the management of an organization has to go continuously through three steps: (1) assessing the current level of organizational agility, (2) identifying potential areas for improvement, and (3) planning, executing, and monitoring appropriate improvement actions. It becomes clear that supporting tools are necessary to accompany these steps.

Already at the first step - assessing the current level of agility - an organization is faced with a difficult challenge. The assessment of agility implies that the components of an agile organization are clearly described and that assessment tools or methods are available. However, there is a lack of a clearly defined framework for explaining agility from an organizational perspective [8], and, hence, there is no consensus about what constitutes an agile organization [9]. As a result, this missing consensus about the determinants and dimensions of organizational agility limits the applicability of research results in practice and restricts the possibility to develop useful assessment tools [10].

The aim of this study is to solve this problem by introducing a maturity model as an assessment tool for organizational agility. The core contributions are a theoretically and empirically grounded structure of the components of organizational agility supporting the efforts of developing a common understanding of organizational agility as well as a useful and practical tool that is able to actually reflect existent patterns of organizational agility in the software and IT service industry.

The remainder of the paper is structured as follows: Section II summarizes available assessment approaches of organizational agility. The research methods used for designing the maturity model are described in section III, while the maturity model itself is introduced in section IV. A first evaluation of the model based on a cluster analysis of empirical data is given in section $\mathrm{V}$. The paper closes with a conclusion and a description of further research opportunities in section VI.

\section{LITERATURE REVIEW}

Due to the missing consensus about what determines organizational agility (see [9], [11] for a detailed discussion), a universal definition is also missing. The literature contains a huge variety of more or less comprehensive definitions, each heavily influenced by context and application domain. While a 
detailed discussion of these definitions is beyond the scope of this paper, a number of authors have analyzed the differences in definitions (e.g. [7], [8], [12], [13]).

For this work, two definitions have been selected as a basis that fits well into the software and IT service context and complement each other in terms of content. First, the definition of Yusuf, Sarhadi, and Gunasekaran [14] generally describes the prevalent situation in the industry under consideration and emphasizes the role of customers as well as the importance of internal capabilities, structures, and people. They define agility as "the successful exploration of competitive bases (speed, flexibility, innovation proactivity, quality and profitability) through the integration of reconfigurable resources and best practices in a knowledge-rich environment to provide customer-driven products and services in a fast changing market environment" [14, p. 37]. This definition can be further extended to explain agility as "an effective integration of response ability and knowledge management in order to rapidly, efficiently and accurately adapt to any unexpected (or unpredictable) change in both proactive and reactive business / customer needs and opportunities without compromising with the cost or the quality of the product / process" [15, p. 411]. Here, the often unpredictable nature of change is further underscored. In addition, both definitions point out the essential role of knowledge in coping with these changes.

Taking these definitions as a foundation, the literature was analyzed according to existing assessment approaches of organizational agility prior to developing the maturity model. A useful summary is given in [16]. In general, these approaches can be roughly categorized into three groups: The first group consists of approaches assessing agility by various metrics. However, these approaches only focus on capabilities, omitting drivers or enablers of agility [16], and are often focused on specific subareas of an organization, for instance marketrelated activities [15] or the supply chain [17]. The second group utilizes methods like the analytic hierarchy process (AHP) to determine overall agility (e.g. [18]), while the third group is based on fuzzy logic (e.g., [16], [19]).

The available approaches suffer from some limitations regarding their applicability to determine the level of organizational agility in practice. This weakness stems either from a too specialized orientation and, hence, an insufficient reflection of the whole organization with its interaction of people, structures, process, and technologies, as outlined above, or from the utilization of relatively complex algorithms, limiting an intuitive and ad hoc usage by management. In addition, although the available approaches are able to determine the current state of agility, they normally do not support management in suggesting further actions for improvement or development.

The identified requirements of a comprehensive representation of the whole organization, an intuitive tool that is easy to use, a determination of the current state of organizational agility, and directions for further improvement can be fulfilled with a maturity model. A maturity model describes and determines the state of perfection or completeness (i.e., the maturity) of certain objects. The progress in maturity can be observed and managed by the definition of maturity stages or levels that measure the completeness of the analyzed objects via different sets of (multidimensional) criteria [20]. This explanation is well reflected in the definition by Becker, Knackstedt, and Pöppelbuß: "A maturity model consists of a sequence of maturity levels for a class of objects. It represents an anticipated, desired, or typical evolution path of these objects shaped as discrete stages. Typically, these objects are organizations or processes" [21, p. 213].

A systematic mapping study analyzing the field of maturity model research shows that there are no maturity models available tackling the field of organizational agility or agility in general [20]. This lack underscores the assumption that the introduced maturity model is able to contribute to the field of assessing organizational agility by proposing a new approach that has not been available yet.

\section{METHOD}

This study follows a design science research approach [22][24], with the purpose of developing a maturity model to assess organizational agility. Hereby, the main goal is to build a maturity model that is applicable in the software and IT service industry. To fulfill this aim, the development is based on theoretical work as well as empirical evidence.

Following [24] a typical design science project includes four basic phases: analysis, design, evaluation, and diffusion. The focus of this study is in the design and evaluation phases by describing the elements and the development of the maturity model, as well as a first proof of concept, by discussing the results of a cluster analysis in the targeted industry. The analysis phase has already been conducted prior to the work presented here and includes stating the problem relevance, formulating the research objective, and searching for existing solutions. The need for a comprehensive organizational view on agility is justified in detail in [9], [25], and an extensive literature review on maturity models is given in [20]. Both aspects have been briefly summarized in sections I and II.

Many maturity models are developed on a purely conceptual basis, and their utility is evaluated afterward, mostly by case studies. A portion of available maturity models is completely lacking any kind of empirical evaluation [20]. For the maturity model developed in this study, a different approach has been chosen to ensure its grounding in theory as well as in empirical evidence. In addition to a careful review of agility frameworks in the analysis phase [9], an exploratory quantitative survey with the overall aim of identifying the elements of an agile organization has been carried out worldwide among organizations of the software and IT service industry. This procedure prior to the design phase allows the author to include empirical evidence already in the initial design of the maturity model and, therefore, enhances its quality and applicability from the very start.

With the survey 437 valid and complete responses were collected. The sample is summarized in table I. The complete questionnaire and comprehensive descriptive results are found 
TABLE I

SURVEY SAMPLE CHARACTERISTICS

\begin{tabular}{|l|r|r|}
\hline Characteristic & Total & Ratio \\
\hline Role within the organization: & 127 & $29.1 \%$ \\
Chief Executive Officer & 36 & $8.2 \%$ \\
Chief Information / Technology Manager & 59 & $13.5 \%$ \\
IT / ICT Manager & 155 & $35.5 \%$ \\
Enterprise / IT Architect & 60 & $13.7 \%$ \\
Other (e.g. Managerial Board Members, & & \\
other Senior Managers, ...) & $\mathbf{4 3 7}$ & $\mathbf{1 0 0} \%$ \\
\hline Location of the organization: & 259 & $59.3 \%$ \\
Europe & 104 & $23.8 \%$ \\
North America & 39 & $8.9 \%$ \\
Asia & 35 & $8.0 \%$ \\
Other (e.g. Columbia, South Africa, Brazil, & & \\
Australia,...) & $\mathbf{4 3 7}$ & $\mathbf{1 0 0} \%$ \\
\hline Size (no. of employees) of the organization: & & \\
less than 10 & 95 & $21.7 \%$ \\
10 to 49 & 87 & $19.9 \%$ \\
50 to 249 & 87 & $19.9 \%$ \\
250 or more & $38.2 \%$ \\
n.a. & $0.2 \%$ \\
& $\mathbf{4 3 7} \%$ \\
\hline
\end{tabular}

in [26]. The survey results are used to identify possible dimensions of organizational agility by exploratory factor analysis [27]. In addition, a cluster analysis has been carried out to identify patterns of agile organizations. These clusters are used for a first proof-of-concept evaluation by comparing them to the structure of the developed model in section V.

\section{Design of the Organizational Agility MATURITY MODEL}

This section introduces the Organizational Agility Maturity Model. Fig. 1 illustrates the structure consisting of three dimensions and four maturity stages. The development of the dimensions and stages is described subsequently. This structure is already the result of the second development iteration. The first version of the model had five maturity stages. However, the cluster analysis of the obtained survey data revealed that this structure of stages is not suitable to represent the empirical patterns of organizational agility appropriately (see section V).

Although the highest maturity stage is always the best one theoretically, many maturity models state that the highest stage should not automatically be the goal for every organization using the model. This is consistent with a perspective on maturity models where every stage yields a set of potential improvements. So, every organization has to individually assess its "optimal" stage. This has disadvantages for the practical applicability. Different interpretations and viewpoints may lead to difficulties for organizations in finding this optimal degree of maturity [20], [28], [29].

For the Organizational Agility Maturity Model, another approach has been chosen that is more related to the life cycle of an organization [29] that is going to become agile. The difference is that the single stages are not only seen as desirable improvement, but rather a representation of steps while evolving over time. Hence, the highest maturity stage is always the "final" goal. Although these differences are only nuances, they are important for interpretation and usage of the model [20], [29]. Therefore, the maturity model should be used by organizations that have the clear objective of achieving organizational agility and want to use the maturity model as a roadmap in accompanying this transition.

\section{A. Dimensions}

The proposed maturity model consists of three dimensions, each of them further detailed into two sub-dimensions. This structure was obtained by conducting an exploratory factor analysis on survey data from the software and IT service industry (see section III). Due to space restrictions, the whole factor analysis cannot be presented here in detail. Tables II and III contain a summary of the results and illustrate the obtained factor structure. In addition, table VI in the appendix lists the assessment items for every dimension. For more information about the survey, please refer to [26], [27].

The conducted survey includes agility-related elements extracted from 28 frameworks describing agility [9]. Hence, the dimensions of the maturity model incorporate a structure of organizational agility that is grounded in theory and based on the empirical investigation also existent in practice. The content of every dimension is described below:

Agility Prerequisites are the degree to which the people of an organization share agile values (mental prerequisites) and to what extent the organization establishes the required technological prerequisites to support agility.

- Agile Values include the establishment of an organizational culture following agile values like proactivity, responsiveness, trust, support of proposals and decisions of employees, and the handling of change as opportunity and chance. This culture is measured by the degree to which the agile values have disseminated throughout the organization.

- Technology represents the technological prerequisites supporting organizational agility by enabling efficient communication across all levels and departments; the sharing of information; and the utilization of standardized, comparable, and integrated technologies and information systems. Technology is measured by the dissemination of appropriate technological support across the whole organization.

Agility of People summarizes all necessary capabilities of the members of an organization to translate the agile values into actions. It is further distinguished into the capabilities of the workforce and the capabilities of managers to cope with change.

- Workforce is a very important sub-dimension and comprises mainly the capabilities of employees. They have to be multiskilled to reorganize themselves under changing 


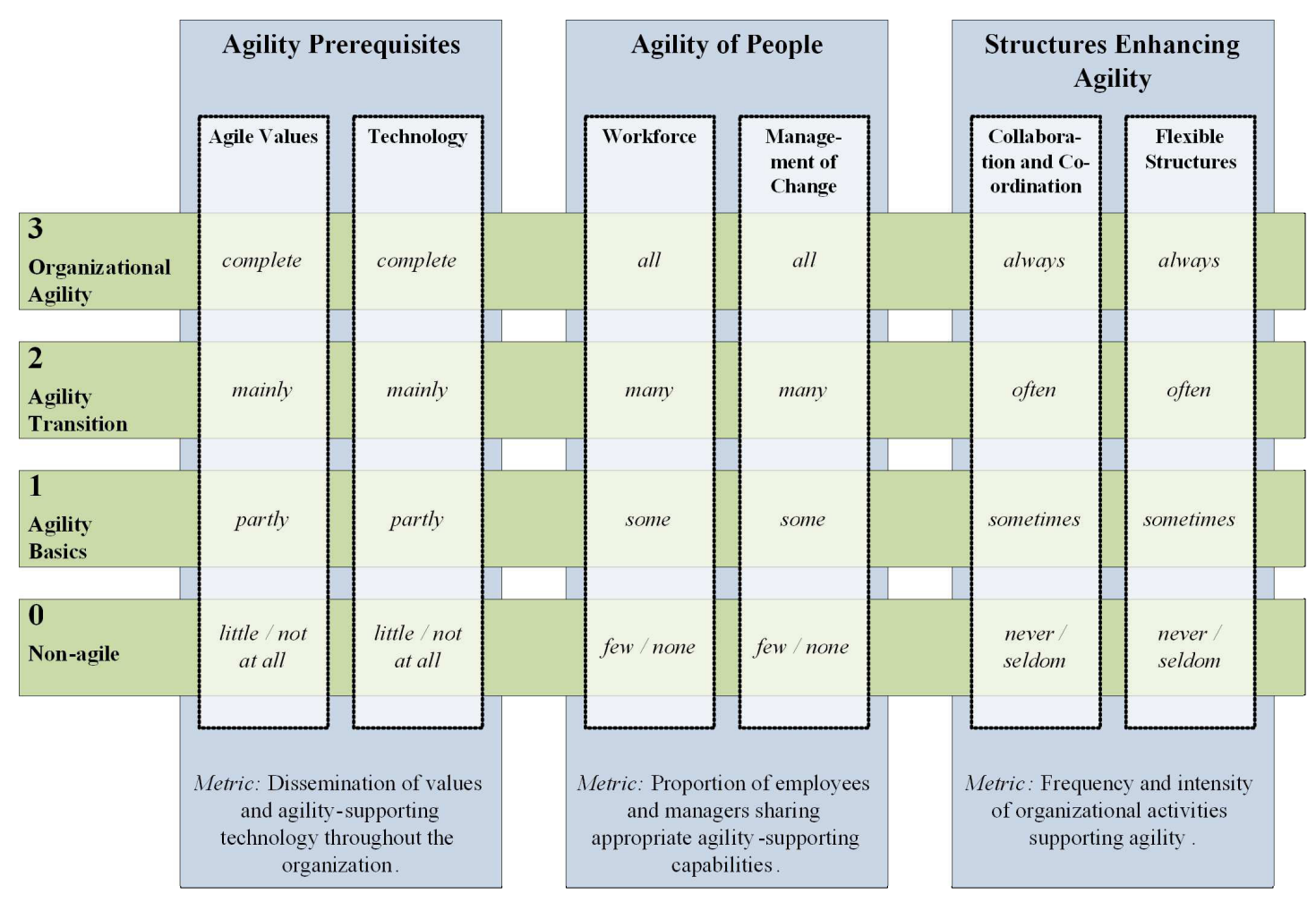

Fig. 1. Structure of the Organizational Agility Maturity Model

conditions. In addition, they should be able and willing to learn from each other to improve themselves continuously, communicate in a trustful way with each other, and take responsibility. Furthermore, they have to be able to think and act with quality and the market in mind. Workforce is measured by the proportion of employees of an organization sharing these capabilities.

- Management of Change involves capabilities, mainly of managers, to cope with changes appropriately and quickly (e.g., changing customer requirements, new markets, innovations, etc.). Managers have to inform the people of the organization accordingly and to inspire them to welcome these changes. In addition, they should be able to act with long-term vision and conduct IT investments strategically. Management of Change is measured by the proportion of managers of an organization sharing these capabilities.

Structures Enhancing Agility describes the ability of an organization to flexibly adopt and change itself combined with an organizational culture that supports collaboration and cooperation on every level.

- Collaboration and Cooperation summarizes activities of internal collaboration between departments and functions of the organization for decision making, new pro$\mathrm{duct} /$ service development, etc. In addition, external cooperation with partners and customers focusing on quality, feedback, and intensive information sharing is covered by this sub-dimension. It is measured by the frequency of organizational activities enabling and supporting collaboration and cooperation.

- Flexible Structures describes the ability of the organization to quickly adapt organizational structures and processes to implement changes and stay competitive. Furthermore, it includes activities that enable quick decisions and a change of authorities when needed. Flexible Structures is measured by the frequency of organizational activities in establishing and incorporating flexibility.

\section{B. Maturity Stages}

The proposed maturity model consists of four distinct maturity stages that are assessed independently for every sub-dimension (see table VI). So, it may happen that an organization holds different maturity stages in the single subdimensions at a certain time. This difference is intended because the approach reflects the real state of the transition towards an agile organization, and it is unlikely that an organization is able to improve every aspect simultaneously and at the same pace. In addition, this approach enables an organization to determine further actions for a suitable path of improvement (see section V).

All six sub-dimensions are treated as equally important and the overall maturity score is simply the average of the single maturity stages. This unweighted and equal treatment is justified because the exploratory factor analysis revealed relatively equal proportions of explained variance between 0.09 and 0.17 for every factor (see Table III). 
TABLE II

SUMMARY OF OBLIMIN ROTATED FACTOR ANALYSIS RESULTS

\begin{tabular}{|c|c|c|c|}
\hline Factor & Item & Loading & Comm. \\
\hline \multirow{11}{*}{ F1: Workforce } & capemp6 & 0.92 & 0.87 \\
\hline & capemp7 & 0.84 & 0.80 \\
\hline & capemp 9 & 0.77 & 0.65 \\
\hline & capemp5 & 0.74 & 0.68 \\
\hline & capemp8 & 0.73 & 0.75 \\
\hline & capemp4 & 0.73 & 0.67 \\
\hline & capemp10 & 0.71 & 0.65 \\
\hline & capemp11 & 0.60 & 0.62 \\
\hline & capemp3 & 0.59 & 0.61 \\
\hline & capemp2 & 0.57 & 0.66 \\
\hline & capemp1 & 0.51 & 0.68 \\
\hline \multirow{6}{*}{ F2: Technology } & tech5 & 0.93 & 0.78 \\
\hline & tech6 & 0.78 & 0.63 \\
\hline & tech1 & 0.74 & 0.67 \\
\hline & tech3 & 0.62 & 0.75 \\
\hline & tech2 & 0.57 & 0.72 \\
\hline & tech4 & 0.55 & 0.58 \\
\hline \multirow{7}{*}{$\begin{array}{l}\text { F3: Management } \\
\text { of Change }\end{array}$} & capman 3 & 0.74 & 0.85 \\
\hline & capman5 & 0.72 & 0.73 \\
\hline & capman4 & 0.67 & 0.78 \\
\hline & capman 1 & 0.59 & 0.73 \\
\hline & capman 7 & 0.59 & 0.76 \\
\hline & capman2 & 0.57 & 0.65 \\
\hline & capman6 & 0.53 & 0.71 \\
\hline \multirow{9}{*}{$\begin{array}{l}\text { F4: Collaboration } \\
\text { and Cooperation }\end{array}$} & actorggen 12 & 0.75 & 0.63 \\
\hline & actorggen 13 & 0.66 & 0.66 \\
\hline & actorggen 16 & 0.58 & 0.69 \\
\hline & actorggen 14 & 0.50 & 0.60 \\
\hline & actorggen 10 & 0.45 & 0.67 \\
\hline & actorggen 9 & 0.44 & 0.57 \\
\hline & actorggen6 & 0.37 & 0.67 \\
\hline & actorggen 15 & 0.36 & 0.62 \\
\hline & actorggen 7 & 0.36 & 0.62 \\
\hline \multirow{7}{*}{ F5: Agile Values } & val1 & 0.69 & 0.59 \\
\hline & val5 & 0.68 & 0.61 \\
\hline & val4 & 0.64 & 0.67 \\
\hline & pref5 & 0.51 & 0.52 \\
\hline & pref1 & 0.47 & 0.59 \\
\hline & val2 & 0.46 & 0.51 \\
\hline & val3 & 0.45 & 0.61 \\
\hline \multirow{5}{*}{$\begin{array}{l}\text { F6: Flexible } \\
\text { Structures }\end{array}$} & actorggen 2 & 0.81 & 0.81 \\
\hline & actorggen 3 & 0.78 & 0.76 \\
\hline & actorggen 1 & 0.50 & 0.59 \\
\hline & actorggen5 & 0.43 & 0.51 \\
\hline & actorggen 4 & 0.43 & 0.68 \\
\hline
\end{tabular}

TABLE III

EIgENVALUE, CUMULATIVE EXPLAINED VARIANCE AND CRONBACH'S ALPHA OF FACTORS OBTAINED

\begin{tabular}{|l|l|l|l|l|l|l|}
\hline & F1 & F2 & F3 & F4 & F5 & F6 \\
\hline Eigenvalue & 7.77 & 4.93 & 5.38 & 4.43 & 4.02 & 3.60 \\
\hline Cum. var. explained & 0.17 & 0.28 & 0.40 & 0.50 & 0.59 & 0.67 \\
\hline Cronbach's Alpha & 0.96 & 0.92 & 0.95 & 0.93 & 0.90 & 0.90 \\
\hline
\end{tabular}

TABLE IV

DETERMINATION OF MATURITY STAGES REGARDING AVERAGE ASSESSMENT SCORE

\begin{tabular}{|l|l|}
\hline Average score & Maturity stage \\
\hline$[1,2.5)$ & $0:$ Non-agile \\
{$[2.5,3.5)$} & 1: Agility Basics \\
{$[3.5,4.5)$} & 2: Agility Transition \\
{$[4.5,5]$} & 3: Organizational Agility \\
\hline
\end{tabular}

To determine the maturity stage of an organization, the assessment questions in table VI are used. Then, the average score is calculated for every sub-dimension. Finally, the organization is categorized to one of the maturity stages per sub-dimension according to the respective average score as outlined in Table IV.

The four maturity stages are:

0 - Non-agile: Organizations at maturity stage 0 show no or only rare properties of organizational agility. Agile values are principally unknown, and the technological basis is fragmented and unable to support communication processes effectively. Only a minority of employees and managers share capabilities necessary to implement agile values and actions. Hence, organizational activities for improving collaboration and cooperation and implementing flexible structures do not take place or only happen by chance. It may occur that single sub-dimensions show a higher score, but overall, these organizations are non-agile.

1 - Agility Basics: Organizations at maturity stage 1 share basic properties of organizational agility. Agile values and technological prerequisites underscoring agility are partly implemented in some but not the majority of departments, business areas, teams, or structural levels of the organization. Likewise, some but not the majority of employees share agile capabilities regarding communication, learning, responsibility, and customer-orientation, and some managers in the organization are able to manage change in an appropriate way. Often, these employees and managers are "concentrated" in single teams or departments. Activities to enhance collaboration, cooperation, and flexibility only take place sometimes, either by selective activities showing some "goodwill" or with a higher frequency but limited to a few agile departments or teams. These organizations have already realized and experienced the benefits of organizational agility, but in most cases only in some departments, teams, or situations, and therefore, the organizations only show some agility basics.

2 - Agility Transition: Organizations at maturity stage 2 manage to disseminate agile values and to establish an appropriate technological basis in most parts of the organization. Many employees and managers share the idea of agility and possess corresponding capabilities. Change is mostly welcomed and handled accordingly. In many instances, the organization carries out activities to support and promote teamwork and establishes organizational structures that are flexible enough to cope with upcoming changes. However, organizations at this maturity stage are characterized by weak- 
nesses in one or two sub-dimensions of the model while others are already on a relatively high agility level (see section $\mathrm{V}$ for details). Hence, they are still in a transition phase towards a complete agile organization.

3 - Organizational Agility: Organizations at maturity stage 3 score high in every sub-dimension of the model and have overcome the partial weaknesses of the transition phase. They manage to establish a sufficient technological basis throughout the complete organization, and agile values are shared and accepted completely, too. All employees and managers have the capabilities to successfully work in an agile and changing environment. Collaboration and Cooperation are important aspects of everyday work and the structure is flexible enough to quickly and constantly react to upcoming changes. If any, there are only insignificant exceptions from the described agile attitude and behavior of the whole organization. Therefore, these organizations achieve complete organizational agility.

With this in mind, every maturity stage implies a specific goal while becoming organizationally agile. It is important for an organization to create an awareness of agility as an essential issue for staying competitive [1]. However, a particular solution affecting only one dimension of the maturity model is not sufficient, and the goal for maturity stage 1 is to get a basic understanding of agility with first transfers into practice in every dimension. This will create the foundation to generate agile solutions from the organization's own capacities [1]. Furthermore, the organizational changes that are needed have to be focused and appropriate to the characteristics of the organization, incorporating individual as well as organizational agility-related characteristics [1], [5]. Hence, the goal of maturity stage 2 is to get a clear vision of how organizational agility can be achieved, and based on this vision, a roadmap of the necessary actions has to be developed. Finally, the goal of maturity stage 3 is an equally matched interplay of all dimensions affecting agility: people, organization, and technology [5], [6].

\section{Evaluation: Cluster Analysis}

As a first step to evaluate the applicability of the Organizational Agility Maturity Model, a cluster analysis on the survey data has been performed to assess if the maturity stages are able to represent real-life configurations of organizations. As mentioned in section IV, the initial model had five maturity stages, due to the scales of the assessment questions used (see Table VI). However, after performing the cluster analysis, the lower two maturity stages were united to the form the maturity stage 0 (non-agile, see Fig. 1).

\section{A. Clustering Method}

To perform the cluster analysis, the dimensions of organizational agility have to be represented in the data. As described above, the sub-dimensions of the maturity model emerged from an exploratory factor analysis. Hence, average summed scales above a cut-off value of a factor loading of 0.3 were calculated for every factor [30] and used for cluster analysis.
This procedure allows for the computation of a factor score for every sub-dimension, which is easily interpretable. The usage of the average allows that the original scale is retained [30], and the cut-off value of 0.3 ensures that only the variables that are included in the respective factor affect the resulting factor score (see Table II). The summed scales approach is especially suitable in this context because it is an exploratory research approach [30], [31].

Two important decisions in cluster analysis include the distance measure and the clustering method [31]. The cluster variables are the sub-dimensions of the maturity model. These subdimensions were extracted using an oblique rotation method (oblimin) in factor analysis and are, therefore, correlated to each other. To avoid distorted results because of correlated clustering variables, the Mahalanobis Distance has been used as the distance measure [31].

For clustering, the following procedure is recommended: First, a hierarchical approach should be used to determine the number of clusters, and second, a non-hierarchical approach should be selected to calculate the final cluster solution [31].

Here, a hierarchical approach using the Ward method was selected to estimate the number of clusters. This method is known to maximize in-cluster homogeneity by building clusters with a minimal increase of variance [31]. After that, the final cluster solution was calculated using a nonhierarchical approach, particularly fuzzy clustering [32]. Fuzzy clustering has been chosen because the clusters obtained by crisp non-hierarchical clustering methods turned out to be unstable when choosing randomized starting objects. However, the author recognized that a part of the data was stable. Such situations are well suited for fuzzy clustering because it bases the clustering on a membership function of every object to all determined clusters. In addition, it is possible to extract the "core objects" for further analysis. These objects have a high membership in one specific cluster (e.g., greater or equal to 0.7 ) and represent the most stable part of the data regarding the cluster solution [32]. The computation was carried out using the statistical software R [33].

\section{B. Results and Discussion}

Based on hierarchical clustering with the Ward method, a number of five clusters was the most appropriate solution. The results of the following fuzzy clustering approach are summarized in Table V. It shows the number of objects with different membership thresholds per cluster. Objects with a membership greater or equal to 0.7 have been considered as core objects and are used for further analysis.

To get an understanding of the clusters, Fig. 2 illustrates the mean values of the five clusters for every sub-dimension of the maturity model. Additional boxplots are given in Fig. 3. The first conspicuous aspect of the figure is that the lower part of the graphic is quite empty. This space does not mean that there were no respondents answering at the lower end of the scale used (see table VI) as the boxplots, particularly for cluster 3 , show. But as cluster analysis reveals, they do not form a distinct cluster of their own. For this reason, the number of 
TABLE V

RESULTS OF CLUSTER ANALYSIS (NUMBER OF OBJECTS) FOR DIFFERENT MEMBERSHIP THRESHOLDS $\left(n_{\text {total }}=437\right)$

\begin{tabular}{|l|r|r|r|}
\hline Cluster & Memb. $\geq \mathbf{0 . 5}$ & Memb. $\geq \mathbf{0 . 7}$ & Memb. $\geq \mathbf{0 . 9}$ \\
\hline 1 & 69 & 33 & 11 \\
2 & 65 & 40 & 11 \\
3 & 69 & 45 & 15 \\
4 & 70 & 47 & 28 \\
5 & 55 & 33 & 13 \\
Total & $\mathbf{3 2 8}$ & $\mathbf{1 9 8}$ & $\mathbf{7 8}$ \\
\hline
\end{tabular}

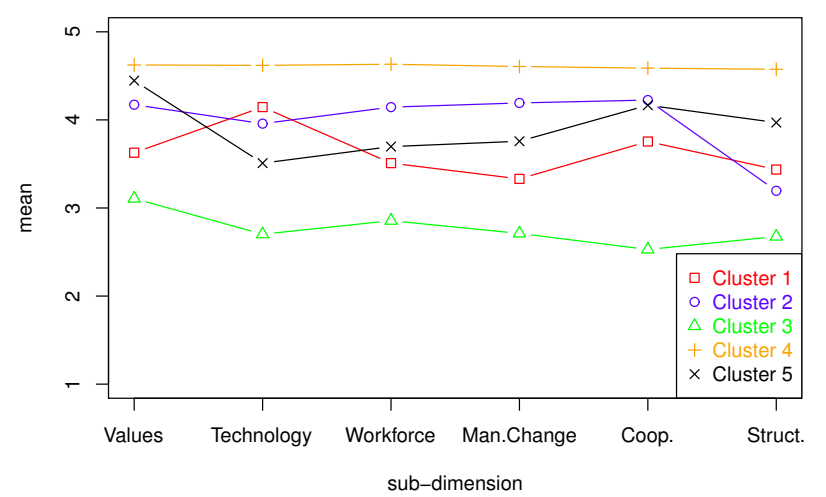

Fig. 2. Mean values of the clusters per sub-dimension

maturity stages has been reduced to four, combining the lower two scale values with no or nearly no agile attributes in the organizations (stage " 0 - non-agile" in Fig. 1).

Furthermore, clusters 3 and 4 are easily distinguishable from the others. The organizations in cluster 3 score at a medium level on average regarding every sub-dimension. This cluster also includes organizations that have a lower agility assessment, but as a closer look into the data reveals, only in some of the sub-dimensions of the maturity model. Therefore, cluster 3 represents stage 1 (Agility Basics) of the maturity model where the covered organizations show initial initiatives and, hence, a basic development towards an agile organization.

Cluster 4, however, represents the opposite side of the scale. The organizations forming cluster 4 show a very high average score for every sub-dimension. As the boxplots in Fig. 3 illustrate, this cluster is the only one where $50 \%$ of the objects score above an average of 4.0 in every sub-dimension, and, hence, describes the proportion of organizations that are most agile in the whole sample. This is represented by stage 3 (Organizational Agility) of the maturity model.

For clusters 1, 2, and 5 the interpretation is more complex. All have differing average values between 3.5 and 4.5 approximately. Therefore, the represented organizations are closer to each other but, nevertheless, show some distinguishing characteristics.
First, for cluster 2, we notice that most of the subdimensions show a relatively equal average score above 4.0 among the covered organizations and indicate a good advancement towards an agile organization. However, the score for the sub-dimension "Flexible Structures" clearly falls behind. This means that these organizations are characterized by a situation where a lot of agile potential (values, technology, capabilities, etc.) is lost due to structural obstacles. Their structures do not allow a fast adoption of processes, strategies, authorities, etc. to changing circumstances, and the agile potential has the risk of sticking to the team level [25]. This result is also consistent with literature where appropriate organizational structures are one central element to achieve organizational agility [6], [34].

Comparing the last two clusters ( 1 and 5) to each other, we recognize that they share an identical pattern for the dimensions "Agility of People" and "Structures Enhancing Agility" (the four sub-dimensions on the right in Fig. 2), with a slightly better average score for cluster 5. However, for the dimension "Agility Prerequisites," they show an opposite trend regarding "Agile Values" and "Technologies." While the organizations covered by cluster 1 score relatively high on "Technology," they score lower on "Agile Values." The opposite occurs in cluster 5.

From an interpretative perspective, this opposition means that the organizations in cluster 1 focus on the dissemination of agility-enhancing technologies. Technology is important because it is generally regarded as an essential enabler or driver of agility [9], [35], [36]. However, a pure concentration on technology also implies some risks. Increased IT spending, for instance, does not automatically lead to greater agility, and other elements represented in the maturity model have to be aligned with technology to achieve organizational agility [37].

The opposite situation is prevalent for the organizations in cluster 5 . They score higher in every sub-dimension with the exception of "Technology." This lack may imply that these organizations are not yet aware of the mentioned role of technology as an enabler of organizational agility. However, in contrast to the organizations of cluster 1 , they already manage to implement a culture based on agile values nearly completely. In addition, this is the only cluster, besides cluster 4 , with an average score of 4.0 or above for the sub-dimension "Flexible Structures."

The organizations in clusters 1, 2, and 5 all would be assigned to stage 2 (Agility Transition) of the maturity model. They support the assumption of a transition phase that applies to the majority of organizations from the analyzed sample. This phase underscores that there are different approaches in becoming organizationally agile by concentrating on different dimensions or sub-dimensions of the maturity model. However, as cluster 4 clearly illustrates, it is important to achieve a balance between every dimension of the model. The considerations above show examples where an unbalanced or too focused improvement path may lead to risks instead of benefits.

The insights gained by conducting the cluster analysis above help to improve the structure of the developed maturity model. The main implications include the reduction of maturity stages 

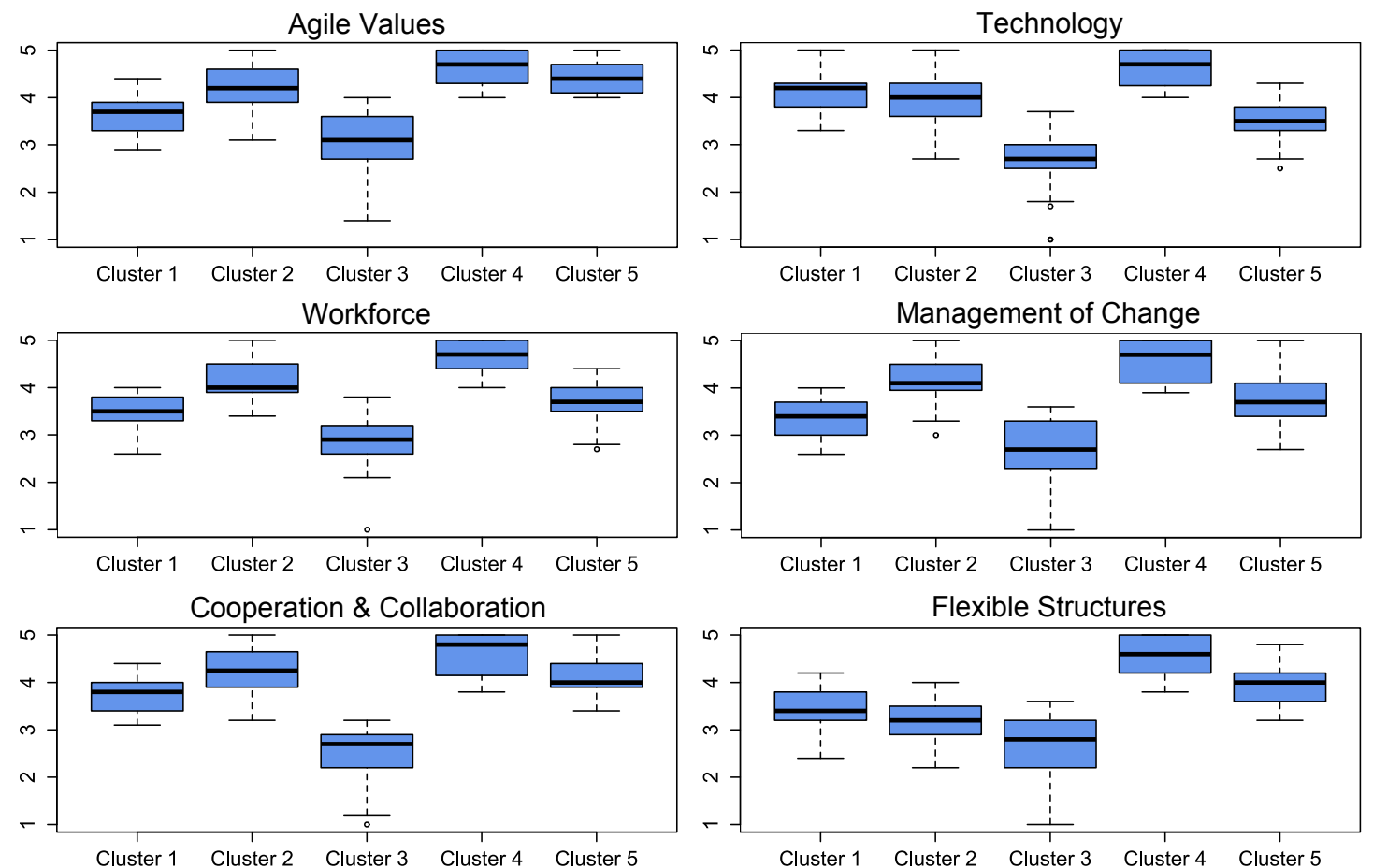

Fig. 3. Boxplots of the clusters per sub-dimension

from five to four to better reflect the empirically identified patterns of agility, a more precise naming of the maturity stages, and a better understanding of potential ways to improve agility by the three clusters assigned to the stage of Agility Transition. Furthermore, the fact that the identified clusters fit to the maturity model and are practically interpretable supports the principal structure and the applicability of the proposed Organizational Agility Maturity Model. Of course, further empirical investigation, for instance by case studies and expert interviews, is still necessary. Nevertheless, the proofof-concept based on a cluster analysis of empirical data and the theoretically and empirically grounded development are already sufficient to confirm that the Organizational Agility Maturity Model is suitable to assess and describe the current state of organizational agility and to assist organizations from the software and IT service industry in taking further actions on their path to organizational agility.

\section{Summary AND CONCLUSION}

This study introduces the Organizational Agility Maturity Model as a new approach to assess organizational agility in the software and IT service industry. To fulfill the aim of achieving practical applicability and simultaneous theoretical grounding and rigorous development, a design-science research approach, including an extensive literature review [9], [11], [20] and an exploratory empirical investigation [26], [27], has been used. The maturity model is structured into three dimensions, each with two sub-dimensions, deduced from exploratory factor analysis, and four distinct maturity stages verified by cluster analysis.
The application of the maturity model creates useful benefits for organizations and underscores the strategic character of organizational agility. First of all, it generates an awareness of what constitutes organizational agility and creates an understanding about the complexity of organizational agility. Furthermore, it may serve as a reference frame to implement a systematic and well-directed approach for improvements and continuous assessment of actions taken.

The empirical investigation and the cluster analysis show that the industry under consideration is actually aware of the benefits of an increased organizational agility. Only a few organizations are classified as "Non-agile" in some dimensions, and they do not even form a separate cluster. Nearly all of the participating organizations have at least reached the stage "Agility Basics" and the majority is situated in stage "Agility Transition," advancing towards "Organizational Agility."

Interestingly, further analysis did not deliver any significant relationship of the clusters to the describing characteristics of the organizations like size, location, role, or customers. This lack indicates that organizational agility can be achieved by every organization that is really willing to take the actions necessary and that the maturity model is generally applicable to organizations in the analyzed industry.

Although an initial evaluation confirmed the applicability of the maturity model, further research should strive for additional validation. Of importance would be qualitative indepth analyses, for instance by case studies or action research approaches, to validate the proposed stages as able to deliver helpful information for individual cases. In addition, the survey 
used to identify the structure of organizational agility, and hence the structure of the maturity model, could be replicated with a different sample in other industries to check if the model is also applicable to other domains.

\section{APPENDIX}

Table VI lists the items that are used to assess the actual maturity stage. They are taken from the survey questionnaire (see section III) and represent the structure of organizational agility that was obtained by exploratory factor analysis [27].

\section{REFERENCES}

[1] J. Bessant, D. Knowles, G. Briffa, and D. Francis, "Developing the agile enterprise," International Journal of Technology Management, vol. 24, no. 5, pp. 484-497, 2002. doi http://dx.doi.org/10.1504/IJTM.2002.003066

[2] P. P. Tallon and A. Pinsonneault, "Competing perspectives on the link between strategic information technology alignment and organizational agility: insights from a mediation model," MIS Quarterly, vol. 35, no. 2 , pp. 463-486, 2011.

[3] K. Petersen and C. Wohlin, "A comparison of issues and advantage in agile and incremental development between state of the art and an industrial case," Journal of Systems and Software, vol. 82, no. 9, pp. 1479-1490, 2009. doi: http://dx.doi.org/10.1016/j.jss.2009.03.036

[4] K. Breu, C. J. Hemingway, M. Strathern, and D. Bridger, "Workforce agility: the new employee strategy for the knowledge economy," Journal of Information Technology, vol. 17, no. 1, pp. 21-31, 2001. doi: http://dx.doi.org/10.1080/02683960110132070

[5] D. Seo and A. I. La Paz, "Exploring the dark side of IS in achieving organizational agility," Communications of the ACM, vol. 51, no. 11, pp. 136-139, 2008. doi: http://dx.doi.org/10.1145/1400214.1400242

[6] S. L. Goldman, R. N. Nagel, and K. Preiss, Agile competitors and virtual organizations: strategies for enriching the customer. New York: Van Nostrand Reinhold, 1995.

[7] P. Kettunen, "Adopting key lessons from agile manufacturing to agile software product development - a comparative study," Technovation, vol. 29, no. 6-7, pp. 408-422, 2009. doi http://dx.doi.org/10.1016/j.technovation.2008.10.003

[8] B. Sherehiy, W. Karwowski, and J. K. Layer, "A review of enterprise agility: concepts, frameworks, and attributes," International Journal of Industrial Ergonomics, vol. 37, no. 5, pp. 445-460, 2007. doi: http://dx.doi.org/10.1016/j.ergon.2007.01.007

[9] R. Wendler, "The structure of agility from different perspectives," in Proceedings of the 2013 Federated Conference on Computer Science and Information Systems, M. Ganzha, L. Maciaszek, and M. Paprzycki, Eds., Kraków, Poland, 2013, pp. 1177-1184.

[10] A. Charbonnier-Voirin, "The development and partial testing of the psychometric properties of a measurement scale of organizational agility,' M@n@gement, vol. 14, no. 2, pp.120-155, 2011.

[11] R. Wendler, "The structure and components of agility - a multiperspective view," Informatyka Ekonomiczna / Business Informatics, vol. 2, no. 28, pp. 148-169, 2013.

[12] E. S. Bernardes and M. D. Hanna, "A theoretical review of flexibility, agility and responsiveness in the operations management literature: toward a conceptual definition of customer responsiveness," International Journal of Operations \& Production Management, vol. 29, no. 1, pp. 30-53, 2009. doi: http://dx.doi.org/10.1108/01443570910925352

[13] A. Gunasekaran and Y. Y. Yusuf, "Agile manufacturing: a taxonomy of strategic and technological imperatives," International Journal of Production Research, vol. 40, no 6, pp. 1357-1385, 2002. doi: http://dx.doi.org/10.1080/00207540110118370

[14] Y. Y. Yusuf, M. Sarhadi, and A. Gunasekaran, "Agile manufacturing: the drivers, concepts and attributes," International Journal of Production Economics, vol. 62, pp. 33-43, 1999. doi http://dx.doi.org/10.1016/S0925-5273(98)00219-9

[15] A. Ganguly, R. Nilchiani, and J. V. Farr, "Evaluating agility in corporate enterprises," International Journal of Production Economics, vol. 118, no. 2, pp. 410-423, 2009. doi: http://dx.doi.org/10.1016/j.ijpe.2008.12.009

[16] Y.-H. Tseng and C.-T. Lin, "Enhancing enterprise agility by deploying agile drivers, capabilities and providers," Information Sciences, vol. 181, no. 17, pp. 3693-3708, 2011. doi http://dx.doi.org/10.1016/j.ins.2011.04.034
[17] M. M. Weber, "Measuring supply chain agility in the virtual organization," International Journal of Physical Distribution \& Lo gistics Management, vol. 32, no. 7, pp. 577-590, 2002. doi: http://dx.doi.org/10.1108/09600030210442595

[18] J. Ren, Y. Y. Yusuf, and N. D. Burns, "A prototype of measuremen system for agile enterprise," in Proceedings of the 3rd. International Conference on Quality, Reliability and Maintenance, G. J. McNulty, Ed. Oxford: University of Oxford, 2000, pp. 247-251.

[19] N. C. Tsourveloudis and K. P. Valavanis, "On the measurement of enterprise agility," Journal of Intelligent and Robotic Systems, vol. 33, pp. 329-342, 2002. doi: http://dx.doi.org/10.1023/A:1015096909316

[20] R. Wendler, "The maturity of maturity model research: a systematic mapping study," Information and Software Technology, vol. 54, no. 12 pp. 1317-1339, 2012. doi: http://dx.doi.org/10.1016/j.infsof.2012.07.007

[21] J. Becker, R. Knackstedt, and J. Pöppelbuß, "Developing maturity models for IT management," Business \& Information Systems Engineering, vol. 1, no. 3, pp. 213-222, 2009. doi: http://dx.doi.org/10.1007/s12599009-0044-5

[22] A. R. Hevner, S. T. March, J. Park, and S. Ram, "Design science in information systems research," MIS Quarterly, vol. 28, no. 1, pp. 75105,2004

[23] K. Peffers, T. Tuunanen, M. a. Rothenberger, and S. Chatterjee, "A design science research methodology for information systems research," Journal of Management Information Systems, vol. 24, no. 3, pp. 45-77, 2007. doi: http://dx.doi.org/10.2753/MIS0742-1222240302

[24] H. Österle, J. Becker, U. Frank, T. Hess, D. Karagiannis, H. Kr cmar, P. Loos, P. Mertens, A. Oberweis, and E. J. Sinz, "Memorandum on design-oriented information systems research" European Journal of Information Systems, vol. 20, no. 1, pp. 7-10, 2010. doi: http://dx.doi.org/10.1057/ejis.2010.55

[25] R. Wendler and A. Gräning, "How agile are you thinking? - an exploratory case study," in Proceedings of the 10th International Conference on Wirtschaftsinformatik, WI 2.011, A. Bernstein and G. Schwabe, Eds., no. February, Zurich, Switzerland, 2011, pp. 818-827.

[26] R. Wendler and T. Stahlke, "What constitutes an agile organization? descriptive results of an empirical investigation," TU Dresden, Dresden, Tech. Rep. 68, 2014. [Online]. Available: "http://nbn-resolving.de/urn: nbn:de:bsz:14-qucosa-130916"

[27] R. Wendler, "Dimensions of organizational agility in the software and IT service industry - insights from an empirical investigation," unpublished, currently under journal review at the time of submission, 2014.

[28] H. J. Kohoutek, "Reflections on the capability and maturity models of engineering processes," Quality and Reliability Engineering International, vol. 12, pp. 147-155, 1996

[29] T. McBride, "Organisational theory perspective on process capability measurement scales," Journal of Software Maintenance and Evolution: Research and Practice, vol. 22, pp. 243-254, 2010. doi: http://dx.doi.org/10.1002/smr.v22:4

[30] C. DiStefano, M. Zhu, and D. Mîndrila, "Understanding and using factor scores: considerations for the applied researcher," Practical Assessment Research \& Evaluation, vol. 14, no. 20, pp. 1-11, 2009

[31] J. F. Hair, W. C. Black, B. J. Babin, and R. E. Anderson, Multivariate data analysis, 7th ed. Harlow: Pearson Education, 2014.

[32] L. Kaufman and P. J. Rousseeuw, Finding groups in data: an introduction to cluster analysis. Hoboken, NJ: John Wiley \& Sons, 2005.

[33] R Core Team, "R: A language and environment for statistical computing," Vienna, Austria, 2013. [Online]. Available: "http://www. r-project.org/"

[34] S. Nerur, R. Mahapatra, and G. Mangalaraj, "Challenges of migrating to agile methodologies," Communications of the ACM, vol. 48, no. 5 , pp. 73-79, 2005. doi: http://dx.doi.org/10.1145/1060710.1060712

[35] D. Vázquez-Bustelo, L. Avella, and E. Fernández, "Agility drivers, enablers and outcomes: empirical test of an integrated agile manufacturing model," International Journal of Operations \& Production Management, vol 27, no 12, pp. 1303-1332, 2007 doi: http://dx.doi.org/10.1108/01443570710835633

[36] Z. Zhang and H. Sharifi, "A methodology for achieving agility in manufacturing organisations," International Journal of Operations \& Production Management, vol. 20, no. 4, pp. 496-512, 2000. doi: http://dx.doi.org/10.1108/01443570010314818

[37] Y. Lu and K. Ramamurthy, "Understanding the link between information technology capability and organizational agility: an empirical examination," MIS Quarterly, vol. 35, no. 4, pp. 931-954, 2011. 
TABLE VI

ITEMS TO ASSESS THE ORGANIZATIONAL AGILITY PER DIMENSION (TAKEN FROM SURVEY QUESTIONNAIRE; SEE SECTIONS III, IV)

\begin{tabular}{|c|c|c|}
\hline Dimension & Assessment items & Scale \\
\hline $\begin{array}{l}\text { Agility } \\
\text { Prerequisites: } \\
\text { Agile Values } \\
\text { [val1-5, } \\
\text { pref1,5] }\end{array}$ & $\begin{array}{l}\text { Our organization values a culture that... } \\
\ldots \text { harnesses change for competitive advantages. } \\
\ldots \text { considers team work as integral part. } \\
\ldots \text { accepts and supports decisions and proposals of employees. } \\
\ldots \text { is supportive of experimentation and the use of innovative ideas. } \\
\ldots \text { considers changing customer-related requirements as opportunities. } \\
\text { Our organization prefers... } \\
\ldots \text { a proactive continuous improvement rather than reacting to crisis or "fire-fighting". } \\
\ldots \text { market-related changes (e.g. new competitors, preferences) to generate news opportunities. }\end{array}$ & $\begin{array}{l}\text { 1: not at all } \\
\text { 2: little } \\
\text { 3: partly } \\
\text { 4: mainly } \\
\text { 5: completely }\end{array}$ \\
\hline $\begin{array}{l}\text { Agility } \\
\text { Prerequisites: } \\
\text { Technology } \\
\text { [tech1-6] }\end{array}$ & $\begin{array}{l}\text { Our organization has Information Systems and Technologies that... } \\
\ldots \text { make organizational information easily accessible to all employees. } \\
\ldots \text { provide information helping our employees to quickly respond to changes. } \\
\ldots \text { are appropriate to our needs and allow us to be competitive in the marketplace. } \\
\ldots \text { enable decentralization in decision making. } \\
\ldots \text { are integrated amongst different departments and/or business units. } \\
\ldots \text { are standardized or comparable amongst different departments and/or business units. }\end{array}$ & $\begin{array}{l}\text { 1: not at all } \\
\text { 2: little } \\
\text { 3: partly } \\
\text { 4: mainly } \\
\text { 5: completely }\end{array}$ \\
\hline $\begin{array}{l}\text { Agility of } \\
\text { People: } \\
\text { Workforce } \\
\text { [capemp1-11] }\end{array}$ & $\begin{array}{l}\text { Our employees... } \\
\ldots \text { are able to act with a view to continuous improvement of our products, services, processes, and/or working } \\
\text { methods. } \\
\ldots \text { are able to sense, perceive, or anticipate the best opportunities which come up in our environment. } \\
\ldots \text { are able to meet the levels of product and/or service quality demanded by our customers. } \\
\ldots \text { use a broad range of skills and can be applied to other tasks when needed. } \\
\ldots \text { communicate with each other with trust, goodwill, and esteem. } \\
\ldots \text { are ready to learn and are prepared to constantly access, apply and update knowledge. } \\
\ldots \text { are in general always willing to continuously learn from one another and to pass their knowledge to others. } \\
\ldots \text { obtain and develop appropriate technological capabilities purposeful. } \\
\ldots \text { can re-organize continuously in different team configurations to meet changing requirements and the newly } \\
\text { arising challenges. } \\
\ldots \text { are self-motivated. } \\
\ldots \text { take responsibility and think in a business-like manner. }\end{array}$ & $\begin{array}{l}\text { 1: none } \\
\text { 2: few } \\
\text { 3: some } \\
\text { 4: many } \\
\text { 5: all }\end{array}$ \\
\hline $\begin{array}{l}\text { Agility of } \\
\text { People: } \\
\text { Management of } \\
\text { Change } \\
\text { [capman1-7] }\end{array}$ & $\begin{array}{l}\text { Our managers... } \\
\ldots \text { maintain an informal management style with focus on coaching and inspiring people. } \\
\ldots \text { understand the value of IT investments from a company-wide perspective. } \\
\ldots \text { have the knowledge and skills necessary to manage change. } \\
\ldots \text { are able to quickly implement changes in products and/or services. } \\
\ldots \text { are able to recognize future competitive advantages that may result from innovations in products, services, } \\
\text { and/or processes. } \\
\ldots \text { are able to flexibly deploy their resources (material, financial, human, ... ) to make use of opportunities and } \\
\text { minimize threats. } \\
\ldots \text { manage the sharing of information, know-how, and knowledge among employees appropriately. }\end{array}$ & $\begin{array}{l}\text { 1: none } \\
\text { 2: few } \\
\text { 3: some } \\
\text { 4: many } \\
\text { 5: all }\end{array}$ \\
\hline $\begin{array}{l}\text { Structures } \\
\text { Enhancing } \\
\text { Agility: } \\
\text { Collaboration } \\
\text { and } \\
\text { Cooperation } \\
\text { [actorggen6,7, } \\
9,10,12-16]\end{array}$ & $\begin{array}{l}\text { In our organization, we... } \\
\ldots \text { jointly and intensively operate throughout different functions and/or departments for strategic decision } \\
\text { making. } \\
\ldots \text { encourage early involvement of several departments and/or functions in new product and/or service } \\
\text { development. } \\
\ldots \text { inform ourselves systematically about information technology innovations. } \\
\ldots \text { strategically invest in appropriate technologies and have a clear vision how IT contributes to business value. } \\
\ldots \text { monitor the performance of our partners and subcontractors very closely. } \\
\ldots \text { select our partners and subcontractors by quality criteria (rather than pure cost-based decisions). } \\
\ldots \text { align all our activities to customer requirements and needs. } \\
\ldots \text { encourage compilation and internal dissemination of information on customers needs. } \\
\ldots \text { closely collaborate with and encourage fast feedback from our customers. }\end{array}$ & $\begin{array}{l}\text { 1: never } \\
\text { 2: seldom } \\
\text { 3: sometimes } \\
\text { 4: often } \\
\text { 5: always }\end{array}$ \\
\hline $\begin{array}{l}\text { Structures } \\
\text { Enhancing } \\
\text { Agility: } \\
\text { Flexible } \\
\text { Structures } \\
\text { [actorggen1-5] }\end{array}$ & $\begin{array}{l}\text { In our organization, we... } \\
\ldots \text { scan and examine our environment systematically to anticipate change. } \\
\ldots \text { react to approaching changes by immediately updating our business strategy. } \\
\ldots \text { react to approaching changes by immediately updating our processes. } \\
\ldots \text { are quick to make appropriate decisions in the face of market- and/or customer-related changes. } \\
\ldots \text { change authorities when tasks change. }\end{array}$ & $\begin{array}{l}\text { 1: never } \\
\text { 2: seldom } \\
\text { 3: sometimes } \\
\text { 4: often } \\
\text { 5: always }\end{array}$ \\
\hline
\end{tabular}

